\title{
Bresson and Mimesis
}

\author{
By Thomas Tam
}

Spring 2004 Issue of KINEMA

\section{BRESSON AND THE PROBLEM OF MIMESIS}

Is there a problem of mimesis in Bresson's conception of cinematography? How does Bresson situate his art in relation to this concept? Is the Bressonian system of cinematography not mimetic in nature after all? Everything in Notes on Cinematography seems to suggest the opposite. As we know, Bresson contrasts his art of cinematography to the art of the theatre. To him, the theatre is a conventionalized practice whose essence consists in the simulation of reality, whereas cinematography presents us with persons and objects such as they are in the real world. The theatre uses actors who act in an expressive way, whereas cinematography uses models who are expressionless. One is imitative, while the other should not be - 'being' as against 'seeming'. Bresson sums up the difference: 'Cinematography films: emotional, not representational.' (NC, p. $90)^{(1)}$

Yet this cryptic remark needs all its interpretations. For how can cinematography not be representational when its medium is the filmic image itself? It seems even more paradoxical in that Bresson's oeuvre belongs to the purest of narrative cinema, and narration, as we know, is fiction and drama. A moment's reflection suffices to show that there may be a deeper affinity between the theatre and cinematography than their oppositions might suggest, for each cinematographic element, such as the model, the automatic movement, the trained voice etc., corresponds to a parallel element of the theatre; and these elements, outside of the narrative form of cinema, lose their function and application. Cinematography is in essence a system of narrative art or fictional representation, though (to anticipate my argument) this representation is problematic to its utmost in that it is worked from within by mimesis. The paradox of Bresson lies in that he at once retains and rejects representation - which means that he differs it from itself. Mimesis and representation in cinematography are not circumscribable concepts, and we have to see how Bresson concretely comes to grips with them in his system.

The starting point of the whole mimetic problem concerns the filmic image, and Bresson discerns here a great obstacle to cinematography. The obstacle is twofold and both are related to the photographic nature of the filmic image itself. Firstly, a photograph, as we know, is an image that objectively reproduces the object placed before the camera. For this reason, there is a greater sense of reality in it than in all the other kinds of image. Not only does it have a greater resemblance to the object it represents, it also refers us back to the existence of the object. For whatever is filmed must have existed. A photographic image can serve to provide therefore documentary evidence for the reality of its object. It makes us see the object as it is in itself. In traditional Cinema where actors are used, the filmic image, apart from the fiction it represents, necessarily reveals the reality of the actor, which is essentially his acting. Thus Bresson says: "CINEMA films are historical documents whose place is in the archives: how a play was acted in 19 by Mr X, Miss Y." (NC, p. 6)

Now, this greater reality of the filmic image actually diminishes the reality of its representation. For, if a filmic image lays bare to the spectator the acting of actors, it undermines thereby his belief in the filmic representation itself. To put it paradoxically, a greater sense of reality in the filmic image only highlights the falsity of the image.

This drawback has a second aspect. For not only does the filmic image manifests the reality of the actor, it also let us glimpse through to the reality of the man the actor is. Bresson says: "A CINEMA film reproduces the reality of the actor, at the same time as that of the man he is being." (NC, p. 91)

Bresson calls this second reality the 'factual existence' of the actor. It is the man behind his mask and who, like a phantom, haunts the actor in his acting. Now, this factual existence often contradicts what the actor endeavours to represent to us. Bresson notes: "X's film. Two wicked eyes, trying to be good; a bitter mouth made for silence, which never stops talking and contradicting the words as soon as said: Star-system in which men and women have a factual existence (as phantoms)." (NC, p. 37) 
The actor in cinema is in fact more false than the actor on the stage, because he is seen through a 'magnifyingglass'. Contrasted with this, the theatrical actor is entirely absorbed into a world of simulation where there is no question of his real existence. Filmic image has this peculiar property that it always gives us to see more than it should represent. This surplus reality constitutes the first obstacle to cinematography.

The second obstacle looks like the contrary of the first. A photographic image has always less reality than the object it represents, because it is only a copy of that object. There is also the possibility that it further degenerates into just a copy of a copy, a representation of a representation, of reality. As such, it is open to the criticism that Plato levels against art in the Republic, namely, that art is only an imitation of reality or an imitation of an imitation. It does not contain truth because it renders to us only the appearance of objects. Bresson directs the same criticism at Cinema:

A film cannot be a stage show, because a stage show requires flesh-and-blood presence. But it can be, as photographed theatre or CINEMA is, the photographic reproduction of a stage show. The photographic reproduction of a stage show is comparable to the photographic reproduction of a painting or of a sculpture. But a photographic reproduction of Donatello's Saint John the Baptist or of Vermeer's Young Woman with Necklace has not the power, the value or the price of that sculpture or that painting. It does not create it. Does not create anything. (NC, p. 6)

In his book, Bresson consistently uses the term 'photographic reproduction' to designate the kind of image that copies an imitated reality, and 'recording' to designate the filming of objects in their natural existence. In other words, a photographic reproduction is an imitation of an imitation in the Platonic sense of the word. A filmic image of this kind is not comparable to other artistic images, because it is only a second-degree image, one that from which no truth can be extracted. It is a servile copy of its object. Cinema as 'filmed theatre' is comparable only to the photo of an artwork; and it itself is not art. The comparison with the photo is here significant, for it brings to light in the working of Cinema a concept of mimesis that Bresson repudiates. It is the Platonic concept of a mimesis that imitates or reproduces in a servile manner the appearance of objects.

The photographic nature of the filmic image is an obstacle and threat to cinematography because it calls into play such a mimetic operation which turns the film into a dead representation. ${ }^{(2)}$ Bresson's stance is here basically in accord with Plato: To purge art (or cinematography) of the bad mimesis - or, as he puts it: "To defeat the false powers of photography." (NC, p. 108) The mimetic function inherent in the filmic image as photographic image must first be rendered inoperative and ineffectual. Herein lies one of the greatest paradoxes of cinematography. For it is a question of making an image not an 'image', in the sense that it no longer represents some pre-existing thing and to which it refers as its referent. Bresson propounds this paradox in an important statement: "in this Language of Images, One must Lose Completely the Notion of Image. The Images must Exclude the Idea of Image." (NC, p. 61)

How can this be achieved? Bresson has in fact invented several devices for achieving this end, viz. the model, the fragmentation and the automatic movement. But these devices can only be understood in relation to another latent concept of mimesis in cinematography. So let us now turn to this second concept in Bresson's system.

In what consists the art of cinematography? What is cinematography? Bresson gives this definition: "Cinematography Is a Writing with Images in Movement and with Sounds." (NC, p. 5)

This definition does not include the making or the fabrication of images. In a sense, cinematography uses prefabricated images and recorded sounds to create. Bresson says:

Because you do not have to imitate, like painters, sculptors, novelists, the appearance of persons and objects (machines do that for you), your creation or invention confines itself to the ties you knot between the various bits of the real that are caught. There is also the choice of the bits. Your flair decides. (NC, pp. 64-5, translation slightly modified)

The art of cinematography consists solely in the choice and the arrangement of images and sounds objectively recorded by the camera and the tape recorder. Images and sounds are only the raw material for the cinematographer's creation. They are just like colours for the painter, sounds for the musician, stone or 
metal for the sculptor, and words for the poet. The task of the cinematographer is to arrange the images and sounds in a certain order, establishing relations between them, so that a fictional representation, i.e. the film, results. His art is thus analogous to that of the figurative painter who puts colours on the canvas in order to produce a picture of the world. The analogy is not fortuitous, because both arts actually end up with images on a flat surface and these images make visible to us a certain reality, in the strong sense of the word.

There is indeed a very 'classical' aspect in Bresson's thinking in that he always insists that art must be true true to nature and true to reality. One may even discern a latent Aristotelianism in his theoretical language as well as in his cinematographic practice. For how can one attain the true through art, if not, as Aristotle says, by an imitation of the essence of things and not just their appearance? Aristotle thinks mimesis not as a servile copying of reality, but as a creative reconstruction of it according to the essence of things; and for this reason, he considers Poetry to be more truthful than History. Art reconstructs reality, such that reality looks more essential than it is. For Bresson also, one must first dismantle and rebuild everything before one can reach the true. In effect, Bresson does not consider that the real is the true, for, when it is recorded as such by the camera, it is either too 'crude' and objective that it does not correspond to what we see; or else, when it is what we perceive, it is too subjective and is often 'deformed by our memory and wrong reckonings'. (NC, p.69)

Only art can restitute the true and the reality from the real. In this regard, Bresson is flagrantly Aristotelian, and this trait of his has not escaped the notice of his critics. Amédée Ayfre, for example, has aptly pointed out that 'Bresson's universe is not that of the everyday reality'. ${ }^{(3)}$ It contrasts sharply with the reality one finds in the films of the neo-realists, like Zavattini and De Sica, in that he does not show us the real existence of people living in a concrete social and historical situation. Rather, his universe is a stylized reality that is essentially attained through a process of abstraction. Ayfre distinguishes between two kinds of abstraction: one 'which proceeds by extension and enables one to classify beings according to their most general characteristics: Man, Animal,' etc., while the other 'proceeds by intensification and which attempts to reach that which makes a being what he is, his essence - let's say his soul'.(4)

It is this latter kind of abstraction that Bresson employs. According to Ayfre, all of Bresson's fictional characters, for example, are stripped to their essentials, and there is no detail of them that does not directly contribute to revealing their inner souls. Nonetheless, this reconstructed reality, though distinct from the everyday universe, is not an impoverished reality, for one finds in it an enhanced realism that makes it seem even truer than the world in which we live. The expressionless faces of the models and their monotonic voices certainly do not render them very much like people in their everydayness, and yet this stylized representation takes away nothing from them as living persons. Strangely enough, we are often surprised to find in them all the complexities and mysteries that only a real person can possess.

Ayfre's notion of abstraction is in essence the Aristotelian concept of mimesis, for it is a creative process that distills the essence from the reality of things. In all likelihood, Bresson does seem to think the cinematographic creation in these terms. And yet, if such were really the case, then cinematography could not possibly be 'non-representational' as Bresson claims it to be. For mimesis produces representation, in the sense that it $r e-$ presents an object (an essence or the true), and this object must appear in its self-sameness. In other words, representation presupposes the identity of an object to which it refers and of which it is a re-presentation, a re-presencing. Something in Bresson seems to speak against this idea. For what, in the final analysis, is the true that constitutes the object of cinematography? Bresson says:

The true is not encrusted in the living persons and real objects you use. It is an air of truth that their images take on when you set them together in a certain order. Vice versa, the air of truth their images take on when you set them together in a certain order confers on these persons and objects a reality. (NC, p. 71)

This remark - one of the most important in the book on the question of mimesis - is startling, for Bresson conceives the true as 'an air of truth' the images possess, and thus as a semblance. It is the images that produce the true by their air of truth, rather than the true that confers an air of truth to the images. The mimetic relation between the imitating and the imitated, or the representation and its original, is completely overturned, such that the representation becomes originary and takes precedence over both the true and the 
reality. Representation can thus no longer be understood as a re-presentation, unless it is taken to mean an other presentation - which is already a presentation of other things.

Bresson here goes decidedly beyond the Aristotelian concept of mimesis towards a more archaic concept which one can already find in Plato, and which Plato seeks precisely to subdue by his philosophical thought. It is the concept of a mimesis as semblance-making, which semblance undermines the very distinctions between semblance and truth, appearance and reality, the same and the other, presence and absence, etc. - and this means: it also undermines itself as semblance. Obfuscating these distinctions, this mimesis can only assume the form of a paradox, for its logic, as Lacoue-Labarthe says, is that of 'the hyperbolic identity of contraries. (5) What is the true is in fact the semblance, and the more the semblance is true, the more it is only a semblance. As we shall see, it is this mimesis that underlies all the important elements in the system of cinematography, making cinematography a highly complex form of art.

Concretely, there are two levels at which we have to examine the working of this mimesis: one is that of the production of the cinematographic image as such, and the other is that of the composition of images, which produces the filmic 'representation' itself. As we have seen earlier, the greatest obstacle to cinematography comes from the photographic nature of the filmic image, for it tends to bring us back to the pre-existing reality of the object, giving us to see thus either too much (a surplus reality) or too little (a reproduced reality) in an image. Making the model not to act is essential, but it is not sufficient, because the image can still reproduce his 'factual existence'.

For cinematography to be an originary presentation of things and not just a re-presentation, the image must first be worked on such that, despite its photographic nature, it does not reproduce its object. Bresson's ingenious solution to this problem consists simply in suspending the sense of the image. By the suspension of its sense, the image seems to cease function as an image. It ceases to be an image of something and withdraws to being just an image. It is thus like an 'empty' or a flat image, apt to take on other meanings in the film. This is why Bresson prescribes: 'Work on insignificant (non-signifying) images.' (NC, p. 11, translation slightly modified) In effect, it is not the immediate reality in individual images that Bresson seeks, for the reality of the film should be fictively produced by the concatenation of images. These non-signifying, non-reproductive images need to be produced by certain cinematographic operations, instead of just being fabricated by the camera. Cinematography thus involves a first level of production - the production of images, and its operations are essentially the fragmentation and the use of models.

Fragmentation can be defined as the cutting up of an object in its separable parts. (cf. NC, p. 84) The eyes, for example, are a separable part of the head, and the hand is a separable part of the body. Cutting the face longitudinally into two halves, however, as in certain clichés of modern cinema, is not fragmentation in the Bressonian sense. It is because fragmentation is not just the production of any 'senseless' image, but has a definite function within the system of cinematography. Its purpose is to arrest the sense of an image. When an image shows only a part of an object, it obstructs our immediate apprehension of the object and we are at a lost as to what object it refers to. With the referent thus left pending, the fragmented images break apart from each other and do not cohere into a coordinated representation.

Let us consider, for example, the fragmented image of a hand. This image is only a hand-image, ${ }^{(6)}$ but it is not at all obvious from such an image alone whose hand it is. In other words, one cannot read from such an image that it is the representation of X's hand. The meaning of the image is thus indeterminate, unless it is juxtaposed to other images.

There is, in Une femme douce, an excellent example of the case in point. At the beginning of the sequence of the young woman's (Dominique Sanda) first visit to the shop, we perceive the image of a hand with a ring on the palm. The image is abrupt, because neither the preceding image (which shows a pair of hands putting down a basin on a chair) nor the following one (which shows the woman entering the shop and queuing at the counter) has any connection with that image. At the image after the next, we see a man (Guy Frangin) standing behind a counter scrutinizing an object in his hand. It is only then that we recognize the hand as belonging to the man, and retroactively, the image takes on the meaning that it is the disclosure of the man's 'world', of his absorption in his everydayness, from which precisely the presence of the woman draws him away. But this signification does not come from the image alone. 
This example also shows up another aspect of fragmentation. It is that fragmentation does not concern only the cutting up of an object, it is also an operation that produces the difference between images. Fragmentation in effect hinders the smooth transition of one image to another, such that the succession of images does not give us the illusion of a coherent representation of things. Let us take the example of spatial representation. Bresson is famous for his cut up spaces and his avoidance of using establishing shots in his films. As a result, the images often baffle one's expectation as to the real spatial relationship between the people or things in a scene. ${ }^{(7)}$ By fragmenting a space into separate and contradicting images, Bresson actually renders the images inapt for the coherent representation of a real space. On the contrary, each of the images is just an image of a certain space, and they construct what Deleuze calls an 'any-space-whatever' [espace quelconque]. ${ }^{(8)}$ It is not the original space that is re-given in the images; rather, the images break down all the connections to that space and they efface themselves as representations.

Apart from fragmentation, the use of models is another operation that counters the mimesis arising from the photo-essence of the filmic medium. This operation is even more important than fragmentation in that the fictional personages form actually the substance of the film, and it is the models who are charged with giving reality and substance to these personae. How does the model render this substance to the camera, without thereby making the images reproductive? It could not be by acting or impersonation. Rather, the models are required simply 'to be themselves', 'to remain what they are', in order to be the fictional personae. (NC, p. 76) But what does it mean for the model 'to be himself'? It does not mean that he shows himself as himself. For if he did, it would be his 'factual existence' that comes through in the image and he would be contradicting the reality of the fictional persona in the film. Paradoxically, it is only by withdrawing into himself, by effacing 'himself' before the camera, that the model succeeds in being himself.

Thus, throughout his book, Bresson constantly refers to the model as that which is 'withdrawn into himself', 'shut up in himself', 'closed', something 'inward', 'hidden', 'not let out', and 'not revealed' - in short, as an 'enigma'. (NC, pp. 48, 67, 93, 35, 106 \& 33) The 'BEING' of the model is in fact this withdrawal, this self-effacement before the camera. His being is not the identity of a self that the filmic image is apt to reproduce. Now, this withdrawal undermines not only the identity of the model, it undermines at the same time the referent of the filmic image. With the withdrawal, the immediate sense of the image is suspended, and we are left with an 'open' image that can take on new significations.

How then does the fictional persona acquire its substance? The substance is made visible by the images when they compose with other images. A transformation takes place within an image when it is in contact with another image, just like a colour is transformed on contact with a neighbouring colour. All the force of cinematography comes from this 'contact and exchange', this 'action and reaction', between the images. The question is how images are to be put together in order to obtain the 'intercommunication and interaction' between them, so that they produce something that surpasses what the individual image signifies, something that is essentially new, unforeseen and unknown. In traditional CINEMA, the images are there purely to serve the film's narrative function, and their association is made in virtue of their internal sense. This sense is established by the actors' conscious acting. And no transformation is therefore possible, for these images are fixed and definitive. (cf. NC, pp. 10-11) 'CINEMA films', as Bresson says, are 'controlled by intelligence'. (NC, p. 44)

Cinematography, on the contrary, regards images in a relation of pure exteriority, just like a colour to a colour, or a musical note to another note; and their association, from a purely formal point of view, is firstly a question of the mechanics of images. What fascinates Bresson in the camera and the tape recorder, to the point that he calls them 'wondrous' and 'sublime machines', is precisely that they give rise to a mechanics of images and sounds. This mechanics brings forth the imperceptible into the perceptible. Bresson writes:

Gestures and words cannot form the substance of a film as they form the substance of a stage play. But the substance of a film can be that thing or those things which gestures and words provoke and which are produced in an obscure way in your models. Your camera sees them and records them. So one escapes from the photographic reproduction of actors performing a play; and cinematography, this new writing, becomes at the same time a method of discovery. (NC, pp. 58-59, translation modified)

The footnote is explicative of this 'seeing' of the camera: "Does so because a mechanics gives rise to the 
unknown, and not because one has found this unknown in advance." (NC, p. 59)

The unknown, which is the substance of the models and of the film, is rendered visible by a certain mechanics. It is the mechanics of images that records and transcribes in all its precision the mechanics of the movement of things - of the movement of the models as automata, for example. This mechanics constrains the mind to see what, for convenience' sake, we can call the 'spiritual' reality. This is why Bresson says that the camera can catch 'what no human eye is capable of catching' (NC, p. 26), not because it can reproduce all the minute details of an object too abundant for a single human perception, but because it is a mechanical instrument that counters all intelligence. The mechanics is at bottom rhythm; and it is rhythm that generates the sense of the film. Thus, in the composition of images, cinematography is primarily an art of the form before it is an art of content. "Bend content to form and sense to rhythms," says Bresson. (NC, p. 58)

Nonetheless, cinematography is not just abstract painting, for, as we said before, its aim is to produce fiction, i.e. a narration. The association of images must therefore contribute to creating a 'representation'. There is no denying that, to a certain extent, cinematography has to follow the logic of representation, but the association of images is defined more by its infringement of this logic than by its conformity to it. What is necessary and important for the representation of an action is often systematically suppressed rather than shown, and it is by this suppression, by ellipsis, that the action as such is more truthfully presented.

The opening sequence of Un condamné à mort s'est échappé is exemplary in this regard. Without going as far as Godard by using 'irrational cut' in associating images, Bresson nonetheless considers images in a relation of pure exteriority, and it is the interstice between the images that is of primordial importance to his films. It is the unsaid, the spacing between images, that carries the full force of reality. For cinematography is to render visible the impalpable reality of things. The reality of Mouchette, for example, is not just the events that she has lived through, events that are describable by the camera. Rather, it is the lived experience of those events as the closing off of all her possibilities that is nakedly given by the film. In the same way, the substance of Mouchette is not that of a psychological subject explicable by its causal relations to the world. It is something unutterable, full of contradictions, but which precisely the film brings to presence, makes seeable in its images. Mouchette acquires this substance as the film goes along, through the fiction and semblance that the film generates.

It is in this sense that cinematography is an originary power of presentation, a mimetic power that is productive of reality. For cinematography does not describe nor explain, but it lets us see and feel. We have to insist here on the fundamental difference between seeing and describing, which is also the difference between cinematography and CINEMA. The seeing is the direct experiencing of reality, a real lived experience provoked by moving images and sounds. This is what constitutes the true of cinematography. It is also what defines the specificity of cinematography as art form and distinguishes it from all the other arts. Thus, Bresson says: 'The true of cinematography cannot be the true of the theatre, nor the true of the novel, nor the true of painting. (What cinematography captures with its own means cannot be what the theatre, the novel, painting capture with their own means.)' (NC, p. 10, translation modified) It is not at all a predilection of Bresson to consider cinematography as an art of the real.

The problem of mimesis is not just a subsidiary question for cinematography, for it constitutes the essential core of Bresson's theoretical reflections on cinema. This problem can be understood in both a negative and a positive sense. In the negative sense, mimesis is a danger for all art, for it dampens the impulse to create and habituates people to the false. Bresson re-appropriates mimesis in an originary sense as the creation of semblance, and this semblance is the power of the true. Thus, despite his apparent conservatism, Bresson is absolutely modern. For him, truth is in fact fiction, and fiction, truth. This explains why, in his relentless search for the true, Bresson is at the same time preoccupied about making himself be believed. One of the last entries in his Notes reads: "Make Yourself Be Believed. Dante in exile, walking in the streets of Verona people whispered to each other that he goes to Hell when he chooses and brings back news from there." (NC, p. 128)

Mimesis should not be a power that gives us 'an illusion of the world' - which in any case, as Deleuze says, is no longer the question of 'modern' cinema. ${ }^{(9)}$ But it is certainly a power that 'restores our belief in the world' in that it continuously creates our world anew as fiction. 


\section{Notes}

1. Robert Bresson, Notes on the Cinematographer, trans. Jonathan Griffin (London: Quartet Encounters, 1986).

2. Bresson says: 'To film someone is not to give him life' and '[living persons and real objects] are killed on film? (NC, p. 13 \& n.)

3. Amédée Ayfre, 'The Universe of Robert Bresson', in ed. James Quant, Robert Bresson (Toronto: Cinémathèque Ontario, 1998), pp. 41-55.

4. Ibid., p. 42.

5. Philippe Lacoue-Labarthe, "Diderot: Paradox and Mimesis," in Typography: Mimesis, Philosophy, Politics, trans. Christopher Fynsk (Stanford, Calif: Stanford University Press, 1998), p. 252. The reader may like to refer to this book for an illuminating discussion of the problem of mimesis in its relation to the paradox

6. We can understand this 'hand-image' in Nelson Goodman's sense of a 'representation-as', which he distinguishes from the denotation of an image. Cf. Nelson Goodman, Languages of Art, 2nd ed. (Indianapolis: Hackett, 1976), Ch. 1, "Reality Remade," pp. 3-43.

7. An excellent example is the scene of the second meeting between Lancelot and Guenièvre at the forest shed in Lancelot du Lac. Cf. the detailed analysis of Kristin Thompson, "The Sheen of Armour, the Whinnies of Horses: Sparse Parametric Style in Lancelot du Lac," in ed. James Quant, Robert Bresson (Toronto: Cinémathèque Ontario, 1998), pp. 339-371.

8. Cf. Gilles Deleuze, Cinema 1: The Movement-Image, trans. H. Tomlinson \& B. Habberjam (London: The Athlone Press, 1986), Ch. 7, pp. 108-122.

9. Gilles Deleuze, Cinema 2: The Time-Image, trans. H. Tomlinson \& R. Galeta (London: The Athlone Press, 1989), pp. 181-182.

\section{Author Information}

Thomas Tam (PhD Sorbonne) is Assistant Professor in the Department of Philosophy at Lingnan University, Hong Kong. He is the Chinese co-translator of Bresson's Notes sur le cinématographe. His main areas of interest are Aesthetics and Contemporary Continental Philosophy. He has recently published in The British Journal of Aesthetics. 